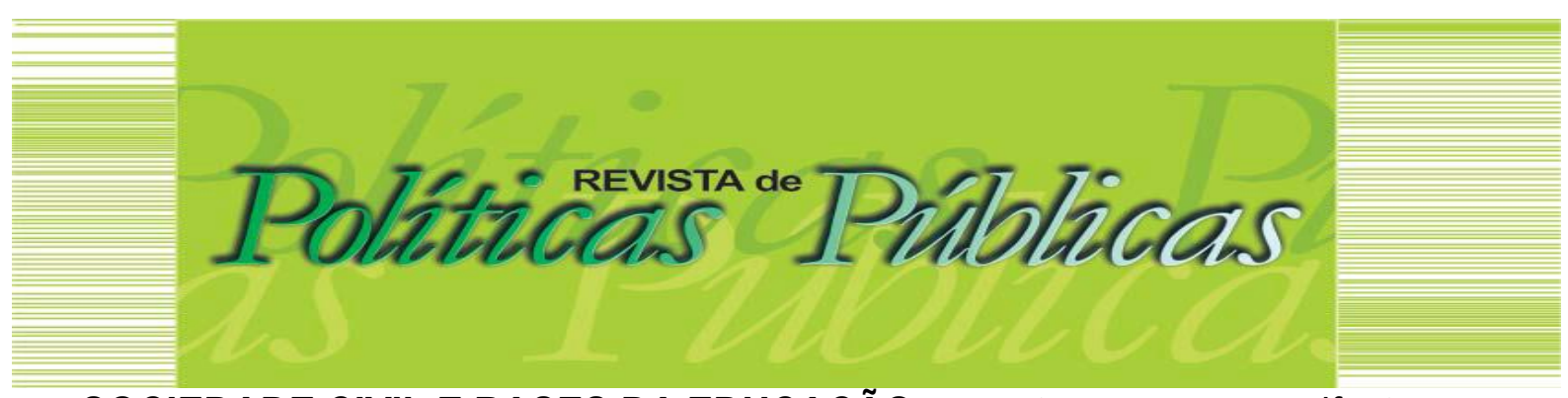

\title{
SOCIEDADE CIVIL E BASES DA EDUCAÇÃO: novo tempo para manifestos ou manifestos para novo tempo?
}

\author{
Urânia Flores da Cruz Freitas ${ }^{1}$
}

\section{Resumo}

Este artigo evidencia historicamente as desigualdades e as ações da sociedade civil inscritas nos manifestos da educação brasileira. Advindo de estudo teórico, pesquisa bibliográfica e documental tem por objetivo analisar como este Ator Rede entendeu e reagiu ao processo de desenvolvimento brasileiro e suas relações no campo da educação. Aponta que os escritos serviram de aporte para a compreensão da conjuntura de cada tempo histórico, pois trazem o cenário em que se inseriram as lutas e as conquistas. Revela como esses atores perceberam ou não as bases que estruturaram a educação no Brasil, como também, a importância dos instrumentos políticos de ação pública. Enfatiza como o movimento histórico das bases de estruturação educacional e social ajuda a pensar a atualidade política.

Palavras-chave: Desenvolvimento. Manifestos da educação. Sociedade civil. Desigualdades. Ação pública.

\section{CIVIL SOCIETY AND THE BASIS OF EDUCATION: new time for manifestos or manifestos for a new time?}

\begin{abstract}
This article evidences historically the inequalities and the actions of the civil society inscribed in the Brazilian education manifestos. Based on a theoretical study, bibliographical and documentary research, it aims to analyze how this ActorNetwork understood and reacted to the Brazilian development process and its relations in the field of education. It points out that the writings served as a contribution to the understanding of the conjuncture of each historical time because they bring the scenario in which they entered, the struggles and the achievements. It reveals how these actors perceived or not the basis that structured education in Brazil, as well as the importance of the political instruments of public action. It also emphasizes how the historical movement of the basis of educational and social structure can contribute on reflect upon the current political time.
\end{abstract}

Keywords: Development. Education manifestos. Civil society. Inequalities. Public action

Artigo recebido em: 20/06/2019 Aprovado em: 15/10/2019 DOI: http://dx.doi.org/10.18764/2178-2865.v23n2p695-715.

\footnotetext{
1 Pedagoga. Doutora em Desenvolvimento, Sociedade e Cooperação Internacional. Professora da Secretaria de Estado de Educação do Distrito Federal. Professora e pesquisadora colaboradora no Centro de Estudos Avançados Multidisciplinares da Universidade de Brasília - CEAM / UnB. E-mail: uraniaflores@gmail.com
} 


\section{INTRODUÇÃO}

Este artigo visa compartilhar parte do resultado da pesquisa de doutorado que discutiu a relação existente entre desenvolvimento e educação. 0 estudo se realizou a partir da observância do modelo de desenvolvimento brasileiro, ou do que intitulamos de desenvolvimento à moda brasileira $\mathrm{e}$ sua relação com as bases que estruturaram a educação no Brasil, ambos observados tanto nas suas dimensões internas quanto externas.

Neste texto discutimos como a sociedade civil, atuante no âmbito da educação, reagiu ao longo da história ao processo de desenvolvimento e suas influências no campo educativo. Assim, é importante salientar que a escolha para entender as ações da sociedade civil foi pesquisar documentos e, em especial, os manifestos em torno da educação brasileira. Esses manifestos foram elaborados muitas vezes por professores e professoras, por personalidades, artistas, escritores (as) e coletividades. Tais escritos serviram de aporte para a compreensão da conjuntura de cada tempo histórico em que foram editados, já que traziam em seus discursos, como já anunciado, o cenário em que se inseriram as lutas, as controvérsias, os conflitos, as contradições, as reivindicações e as conquistas.

A pesquisa e a percepção da conjuntura, por meio dos manifestos, permitiram trazer os atores rede (LATOUR, 2012) envolvidos na dinâmica social, política e econômica tais como: estado, capital, trabalho. Foi possível também, verificar a ação política, os interesses e a ação pública desses atores. Enfim, foi uma escolha que permitiu observar e trazer para o debate e por diversos ângulos, uma mesma realidade. A intenção aqui foi revelar se, e como a sociedade civil percebeu as bases de sustentação social, política, cultural e econômica que podem ter caracterizado a política educacional brasileira. Neste artigo, a opção foi focar nas ações da sociedade civil com vistas a demonstrar por um lado, as possíveis lacunas desse ator no entendimento deste processo, e por outro lado, revelar o papel central de contra hegemonia desses atores, em especial, na atualidade, indiscutivelmente caracterizada por retrocessos na política de educação.

Para entrar no debate em torno do papel da sociedade civil no processo de construção da política pública de educação brasileira, lembramos o texto Valores Proclamados e Valores Reais de Anísio Teixeira (1962). 0 autor descreve a dualidade entre o Brasil real e o oficial, ao afirmar que:

A realidade, porém, é que nos acostumamos a viver em dois planos, o 'real', com as suas particularidades e originalidades, e o "oficial" com os seus reconhecimentos convencionais de padrões inexistentes. Enquanto fomos colônia, tal duplicidade seria explicável, à luz de proveitos que daí advinham para o prestígio do nativo, perante a sociedade metropolitana e colonizadora. A independência não nos curou, porém, do velho vício. Continuamos a ser, [...] nações de dupla personalidade, a oficial e a real (TEIXEIRA, 1962, p. 62). 
SOCIEDADE CIVIL E BASES DA EDUCAÇÃO: novo tempo para manifestos ou manifestos para novo tempo?

Em todo o texto fica clara essa ideia entre o oficial e o real, acrescentamos que em nossa história política e educacional houve a persistência constante em mudar a legislação para não mudar a realidade social. Porque esconder e camuflar a realidade com o propósito de mantê-la como fonte de privilégios para alguns foi e é sempre o valor real. 0 que foi percebido na pesquisa e é possível afirmar com certo nível de segurança é que, no Brasil, na educação, historicamente isso foi feito se utilizando do poder da lei,

Piletti (1991, p. 22) nos ajuda a entender

\begin{abstract}
No campo da educação escolar, enquanto a legislação, seguindo tendências modernas dos países mais desenvolvidos, evoluiu no sentido de uma escola pública - única, gratuita e democrática - aberta a todos, a atuação prática dos poderes públicos mostrou-se bem diferente. Continuamos a ter dois tipos de escola: uma para as classes dominantes, que conduz a Universidade; outro para os pobres que, em geral, limitava-se aos primeiros anos do ensino de $1^{\circ}$. Graus. As leis são feitas, mas não se providenciam recursos para que sejam cumpridas.
\end{abstract}

Importante registrar, que mesmo o processo de democratização do final da década de 1980, e seus avanços, nós não nos curamos do nosso mal e ainda temos muito a fazer e lutar para efetivarmos as mudanças. Portanto, este modo de agir típico da construção histórica da realidade brasileira contribuiu, em parte, para que pudéssemos realizar a discussão sobre em que bases a educação foi estruturada no Brasil. No estudo levou-se em consideração que o Brasil surgiu "sob a égide do modo de produção capitalista fundamentado na desigualdade entre as classes e com foco na expansão do lucro do capital" (FREITAS, 2018, p. 10).

Salientamos que, essa dinâmica da desigualdade e do lucro advinda do modo de produção vigente ganhou potencialidade em uma colônia que não só repetiu, mas potencializou no seu processo de desenvolvimento esses dois fenômenos. A pesquisa revelou que o movimento histórico estudado apontou que a educação brasileira, a partir do período colonial, se firmou sobre bases fundamentadas essencialmente pela busca do dinheiro e pelas desigualdades de gênero, raça, renda e classe. Revelou, ainda, que houve resistência por parte da classe trabalhadora, mas pouca efetividade quanto aos efeitos causados por essa estrutura basilar que necessita ser reestruturada.

Dessa forma, o intuito aqui é mostrar nos documentos (leis, manifestos, cartas), nos instrumentos de gestão e autores, os diferentes períodos e processos no campo da educação, que como dito, apesar dos avanços houve e ainda há muitos retrocessos. Esses estão diretamente relacionados às bases em que a educação foi estruturada no país, como também, com a percepção que teve e tem a sociedade civil sobre essa dinâmica, pois é esse ator que na luta diária estabelece a resistência frente aos poderes constituídos. 
Na história do desenvolvimento desejamos registrar que no Brasil, e em todo o mundo, este estabeleceu relação direta entre a demanda e expansão do ensino e a qualificação da força de trabalho, como também, com as desigualdades regionais, econômicas e sociais. No estudo ficou patente que na história do desenvolvimento, tanto em nível internacional quanto nacional, foi possível perceber, com 0 ator rede dinheiro, que as diferentes formas de desigualdades são as bases de sustentação desses processos.

Tal conceito é aqui utilizado em sua pluralidade, desigualdades, pois ao serem observadas sob a ótica do dinheiro/lucro e suas mais diferentes traduções indicaram, no caso brasileiro, as chaves para a compreensão desta busca. Optamos por analisar essa performance a partir dos aportes da Teoria Ator-Rede de Latour (2012) com os conceitos de ator-rede, tradução e dinheiro; e a partir dos aportes da Dialética do Materialismo Histórico (MARX, 2013), (GRAMSCI, 1968), (ALVES, 2010) com os conceitos de totalidade, contradição, hegemonia, interesse e classe. Diante dessa contextualização partimos, como já anunciado, para a discussão dos manifestos da educação.

\section{NOS (DES) CAMINHOS DOS MANIFESTOS DOS EDUCADORES: sempre convocados!}

A discussão abaixo será norteada pelos primeiros manifestos e cartas da sociedade civil. Essa alternativa se justificou, pois a nosso ver os manifestos, a exemplo das legislações e cartas expressaram, ao mesmo tempo, a dinâmica econômica, cultural, política e educacional de cada época a que se reportaram, como também, os desejos e perspectivas de futuro. Os manifestos acabaram por inspirar e/ou fundamentar a construção de potentes movimentos, leis, decretos e documentos. Portanto, essa escolha como fatos e acontecimentos históricos, políticos, econômicos e sociais nos ajudaram a compreender o passado e o presente, abrindo algumas portas para a passagem do futuro.

Registramos que os manifestos são vistos como importantes marcos na história da educação brasileira, tendo em vista que esses lançaram movimentos, constituíram identidades, sonhos, organizaram e agruparam os signatários. Ressalte-se que nos chamou atenção a diferença entre os signatários dos manifestos das décadas de 1870, de 1930 e de 1959, porque estes eram personalidades, em sua maioria professores, artistas, escritores (as), médicos. Já nos manifestos, a partir da década de 1980, os signatários são entidades representativas, sindicatos, fóruns, centrais sindicais. Tal fato revelou mudanças no tocante à participação social e na organização da sociedade civil no Brasil, na luta em defesa dos interesses da população. Tais mudanças abriram brechas para perceber espaços de gestão com foco na instrumentalização da ação pública. (FREITAS, 2018).

Ação pública é um conceito aqui compreendido, no sentido dado por Lascoume e Lé Galés (2012), como um conjunto de ações e relações que ocorrem em uma multiplicidade de níveis e 
SOCIEDADE CIVIL E BASES DA EDUCAÇÃO: novo tempo para manifestos ou manifestos para novo tempo?

com diferentes atores, que retira a visão do ator Estado, mesmo considerando a sua importância, como o único com o poder de elaborar e realizar as políticas públicas. Em nosso entender, os atores participam da construção, execução e monitoramento das políticas públicas por meio de instrumentos de participação nas decisões públicas que são criados com esse fim. Dessa forma, para desconstruir a lógica da centralidade do Estado, alguns instrumentos de gestão participativa foram sendo reformulados ou criados, tais como: conselhos, comitês, fóruns, todos visando potencializar a ação pública no processo de construção e elaboração das políticas públicas no país.

$\mathrm{Na}$ arena da participação nas decisões públicas em educação concebemos que a instrumentação da ação pública é feita por meio de instrumentos de política pública. Em acordo com a acepção foucaultiana é vista também, como um dispositivo de poder. Esse dispositivo de poder é tão tecnológico e técnico quanto social e político, pois possibilita a organização das relações sociais entre as autoridades públicas governamentais e as demais autoridades envolvidas, sempre em acordo com suas representações, interesses e significados. Sendo importante salientar, ainda, que nessa acepção o poder se encontra por toda parte, ele está e se dá em qualquer lugar. Portanto, "o poder não é só do Estado ou da soberania. O poder são as ações sobre as ações. O poder provoca ações que ora se encontram no campo do direito, ora no campo da verdade" (FERREIRINHA; RAITZ, 2010).

No entanto, e retornando à discussão dos manifestos, independentemente de serem personalidades e/ou entidades, é relevante marcar que os discursos contidos nos manifestos não são considerados como expressões de sujeitos individuais, eles foram compreendidos como atores rede não humanos e humanos (LATOUR, 2012). Atores que estão postos com poder de ação e em campos complexos de forças e de disputas e tensões, como também de debates e consensos no interior da sociedade, e na comunidade escolar. São atores rede de ação coletiva, são participantes da luta pela hegemonia e, também, pela contra-hegemonia.

Nesse sentido, compreender a dinâmica dos atores humanos por meio dos documentos (atores não humanos) que revelam, dentre outras coisas, a dinâmica dos espaços de decisão se revelou importante. Cada vez mais, a classe trabalhadora terá que se organizar para reconquistar direitos, espaços de fala e de ação política, como também, atuar na construção de instrumentos de ação pública que potencializem a democracia e o controle social.

No Manifesto dos Professores da Instrucção Pública da Corte" (1871)1, dentre outras coisas, percebe-se a indignação dos profissionais com a falta de respeito com os professores:

Concidadãos, - Em uma época de patriotismo e de reformas, quando parece despontar nos horizontes da pátria uma nova era de prosperidade, e sobretudo justiça, quando os direitos de uma parte da humanidade oprimida vão ser reconhecidos, quando se dá ao mundo o exemplo de quanto pode a força do direito sobre o direito da força, nesta época em que vibra a corda da generosidade em todos os corações brasileiros, uma classe inteira de 
funcionários públicos, classe talvez a mais importante dos servidores do Estado, vive oprimida, ludibriada, escarnecida, e, o que mais é, humilhada pela injustiça com que os poderes do Estado a apelidam constantemente de ignorante! (MANIFESTO DOS PROFESSORES, 2011, p. 188).

Segundo Freitas (2018), nessa época, o contexto nacional estava propício a mudanças, com os ideais de abolicionismo e de república, e o que parecia era que se inauguraria um tempo de transição política e econômica no país. Era um momento de esperança e exultação, em que diferentes projetos e concepções de Estado estavam em disputa. Esse manifesto foi composto de 4 (quatro) cartas e cada uma destinada a um público e/ou interlocutor específico, a saber: aos concidadãos, ao imperador, aos legisladores e ao ministro dos negócios do império.

Basicamente, na primeira carta do manifesto - aos Concidadãos, os professores denunciam os baixos salários, revelam sua indignação e falam do descaso com a categoria e a profissão por parte do Estado e do Governo, e alertam a população sobre o seu poder real em relação ao Estado e, assim, pedem para ajudar os professores de seus filhos.

Concidadãos, ouvi-nos! Temos até aqui sofrido resignados toda a sorte de injustiças. Agora porém, que a taça transbordou com a repulsa que acabamos de sofrer quando pedimos aos poderes do Estado que nos tirassem ao menos da miséria, tomamos a resolução de vir perante vós, que constituis o poder real da nação, articular as nossas queixas e pedir justiça, não por amor de nós, mas por amor de vós! Sim, por amor de vós! Sois vossos filhos os prejudicados com a nossa humilhação! Que sentimentos de dignidade lhes podemos inspirar no estado de abatimento em que nos achamos?! (MANIFESTO DOS PROFESSORES, 2011, p. 188 apud FREITAS, 2018).

No documento, há o relato de um fato em que um professor da escola primária havia realizado a tradução de um livro, tradução feita em acordo com as regras e a lei. A lei dizia que ao se traduzir um livro, se o mesmo fosse adotado pelo governo haveria um prêmio em dinheiro, mas isso não ocorreu, pois, o valor proclamado não virou um valor real. 0 manifesto assim expressa:

Pois bem, os professores públicos, ou antes os mestres de escola, acreditando na sinceridade da promessa do governo e na igualdade de garantida pela constituição, fizeram alguns esforços com mais ou menos sucesso. Era esse 0 efeito que se pretendia com 0 citado artigo. Um houve que chegou a conseguir que seu compendio fosse adoptado pelo governo, depois de uma luta de quatro anos, em que teve que concorrer com um senador e com mais dois cavalheiros recomendáveis por seus conhecimentos e posição social! Corre ao governo em busca de seu prêmio, e o governo lhe responde: a lei não é clara, não precisa o prêmio; e no entender do governo a adopção já é um prêmio! Mas, Senhor, Considere V. Ex. que a adopção é condição para o prêmio, Ihe torna o importuno. Sim..., mas.... a mente do legislador referia-se a livros de certa importância (!!!) Eis aí, concidadãos, a interpretação das leis quando se trata de mestres escolas! Pois há-se de aviltar um prêmio que se dá aos doutores, dando-o também a um mestre escola?! (MANIFESTO DOS PROFESSORES, 2011, p. 189 apud FREITAS, 2018).

No texto acima, e em várias outras passagens do manifesto percebemos o que afirmou Teixeira (1962), quando se referiu que no Brasil existiam os valores proclamados e os valores reais. Aqui podemos traduzir e afirmar a existência de direitos proclamados e direitos reais. Tal fato é possível 
SOCIEDADE CIVIL E BASES DA EDUCAÇÃO: novo tempo para manifestos ou manifestos para novo tempo?

porque a partir da mesma lei foi dado tratamento desigual entre os professores doutores e os professores primários, o que demonstrou sem sombras de dúvidas a persistência da desigualdade de classe característica do modo de produção capitalista e a desigualdade de tratamento em função do nível de escolaridade, característica da sociedade brasileira.

$\mathrm{Na}$ segunda carta endereçada ao imperador fica registrada a desvalorização dos trabalhadores da educação, em especial da educação primária. Tal fato revelou que a prometida ampliação da oferta e a educação da população não era o foco principal, embora estivesse nos discursos. Essa população era predominamente pobre, negra e feminina. Na terceira carta, que foi encaminhada ao Legislativo, os professores primários se referem a um documento, anteriormente enviado, em que pediam posição sobre a questão do aumento dos salários. Fizeram tal solicitação de aumento por meio de um pedido de isonomia salarial, em relação a outros trabalhadores da educação.

$\mathrm{Na}$ quarta carta, ao Ministro, se referem ao que fora dito em 1856, por Eusébio de Queiróz, sobre a importância e a necessidade da educação primária para o desenvolvimento, social, cultural e econômico. Aqui se pode apontar que houve percepção por parte dos signatários, já nesse período de nossa história, da relação entre educação e desenvolvimento.

\begin{abstract}
Não basta, porém, decretar a instrução primária como uma necessidade social, e proclamála como primeiro elemento de civilização e de progresso; é mister também que o legislador, para não tentar uma obra impossivel e consagrar um princípio estéril, eleve e reabilite perante o espírito público aqueles a quem encarrega o ensino da mocidade, inspirando-lhes a consciência de sua importante missão e o sentimento da própria dignidade, pondo-os longe do alcance da miséria, libertando-os das apreensões do triste futuro que poderão legar a suas famílias, dando-lhes, em uma palavra, meios de decente e honesta subsistência! (MANIFESTO DOS PROFESSORES, 2011, p. 197 apud FREITAS, 2018).
\end{abstract}

No século XIX, a educação foi descentralizada pela Constituição da República de 1891, que instituiu o sistema federativo de governo. A maioria dos autores estudiosos da educação no Brasil, tais como; Saviani (1992), Romanelli (1978), Frigotto (2001) e Cunha (2017) perceberam a dualidade de sistemas educativos herdada do período anterior. Na prática, é possível afirmar que o governo federal ficou com a responsabilidade de criar e controlar o ensino e a instrução em todos os níveis, porém seu foco esteve na classe dominante. Aos estados cabia criar e controlar a educação primária e profissional, que eram fundamentalmente, a escola normal para as mulheres e as escolas técnicas para os homens, com foco na população em geral. Portanto,

No Brasil do século XIX, como nos países da Europa, a montagem do edifício educacional escolar começou pelo alto, isto é, primeiro o ensino superior, depois o secundário. Enquanto isso, paralela e distintamente, algum ensino de primeiras letras era oferecido ao povo. Nos países da Europa onde a reforma protestante se fez sentir, o favorecimento da leitura da Bíblia levou à multiplicação de escolas populares, públicas e privadas. Como este não era 0 objetivo do Estado confessional católico no Brasil, a modesta oferta de ensino primário foi alvo de leis não aplicadas e de meras declarações de intenção de governantes. As elites 
tinham suas próprias escolas primárias, mas preferiam contratar professores particulares para seus filhos, especialmente mulheres europeias (CUNHA, 2017, p. 105).

Com o manifesto e essas discussões, percebe-se a oficialização das desigualdades existentes no país desde a época colonial, e que são fundantes da educação brasileira. A desigualdade de classe, de renda e de raça, em que as escolas secundárias e superiores serviam à educação da classe dominante, predominantemente branca e masculina; e as escolas primária e profissional precárias e com baixos salários para os professores eram para a educação do povo, na sua maioria pobres e negros. A desigualdade de gênero (outro dualismo na educação), em que a escola normal (magistério) era para as meninas e as escolas técnicas para os meninos. Como também, de acordo com D’Ávila (2006) e Cunha (2017) a contratação de professoras primárias, estrangeiras e brancas.

Quando observamos o contexto político e social no século XX, em relação à organização dos trabalhadores vimos a importância do crescimento do trabalhador urbano, que contou com forte influência dos trabalhadores europeus, e foi assim que as primeiras greves operárias começaram no Brasil. Desses movimentos surgiram a Revolta dos Tenentes de 1930, a Revolução Burguesa e a criação do Partido Comunista Brasileiro. Esses movimentos influenciaram substancialmente a política e a economia, como também, a formação da sociedade civil no país (CARVALHO J. M., 2008).

De acordo com Freitas, (2018, p. 183)

Esse momento do país foi marcado, também, pelos intensos conflitos e movimentos sociais ligados ao trabalho nas fábricas. Esses movimentos demonstraram não só a insatisfação com as condições de trabalho disponíveis à época, mas também o crescimento quantitativo da classe que vivia do trabalho assalariado. Tais questões políticas, sociais e econômicas, tanto em nível exógeno quanto endógeno influenciaram o modelo de desenvolvimento e de educação no Brasil.

Ainda segundo a autora, no que tange à educação na década de 1920, houve reformas estaduais de ensino que anunciaram reformas de cunho nacional, mas que só foram instituídas na década de 1930. Entre a década de 1930 e 1960 foram editados mais dois manifestos. Optamos por discutir os manifestos de 1932 e de 1959 conjuntamente, tendo em vista que a maioria dos signatários são os mesmos e termos observado poucos avanços entre as décadas.

No Manifesto dos Pioneiros da Educação Nova de 1932, assinado por 26 signatários, sendo 23 homens e 3 mulheres - e intitulado: A reconstrução educacional no Brasil - ao povo e ao governo, está assim descrito:

Na hierarquia dos problemas nacionais nenhum sobreleva, em importância e gravidade ao da educação. Nem mesmo o de caráter econômico the podem disputar a primazia de reconstrução nacional. Pois se a evolução orgânica do sistema cultural de um país depende de suas condições econômicas, é impossível desenvolver as forças econômicas ou de produção, sem o preparo intensivo das forças culturais e o desenvolvimento das aptidões a invenção e a iniciativa de riqueza de uma sociedade (AZEVEDO et. al., 1984, p. 407). 
SOCIEDADE CIVIL E BASES DA EDUCAÇÃO: novo tempo para manifestos ou manifestos para novo tempo?

$\mathrm{Na}$ citação acima, além de destacar a supremacia da educação, afirmaram que seria impossível o desenvolvimento econômico e produtivo do país sem o desenvolvimento das aptidões e 0 preparo das forças culturais. Essa dinâmica deveria ser implementada sob a responsabilidade do Estado por meio da educação pública. Os signatários defenderam que esse era o caminho para criar "um sistema de organização escolar, à altura das necessidades modernas e das necessidades do país" (AZEVEDO et. al, 1984, p. 408). Queriam uma reforma global na sociedade e na educação.

O manifesto de 1932 visava uma reconstrução social pela renovação da educação, foi inspirado pelos ideais da escola nova e com forte influência do pensamento liberal. De maneira global, o manifesto defendia a escola pública, obrigatória, laica e gratuita, e se baseava na racionalidade científica. Tal proposta estava de acordo com o pedido do então presidente Getúlio Vargas, pois o Brasil estava em um intenso processo de industrialização, mas possuía alta taxa de analfabetismo. Portanto, era preciso investir na educação para preparar e formar a força de trabalho.

Desejamos destacar que no Estado brasileiro, após 1930, tivemos uma atmosfera favorável à formação de espaços de decisão pública, mas seu foco foi centrado em produzir arranjos corporativos. Tais arranjos, de um lado possibilitaram a inclusão de alguns segmentos da sociedade tais como os intelectuais, porém por outro lado deixou de fora outros atores sociais destes espaços decisórios, atores tais como: os pobres, os professores, as mulheres e os negros.

O segundo manifesto, o Manifesto dos Educadores: Mais uma vez convocados Manifesto ao povo e ao governo, assinado por 161 signatários, foi publicado em 1 de julho de 1959. Fez crítica contundente ao processo educativo e de organização da gestão da educação, porque não fez muita diferença ao longo dos 25 anos, e embora admitissem alguns avanços afirmaram que,

\begin{abstract}
Certamente, nesse largo período, tivemos a fortuna de constatar numerosas iniciativas do maior alcance, muitas delas de responsabilidade direta ou sob a inspiração de alguns dos signatários do Manifesto dos Pioneiros da Educação Nova. Mas foram elas ou largos planejamentos, parcialmente executados, ou medidas fragmentárias, em setores isolados da educação ou de influências regionais, sem as conexões indispensáveis com as diversas esferas do aparelhamento escolar, cuja estrutura geral não se modificou, mantendo-se incongruente e desarticulada em suas peças fundamentais (AZEVEDO et al, 2006, p. 205).
\end{abstract}

Isso demonstra a desarticulação das estruturas fundamentais em que não houve conexões com as diversas esferas escolares, onde quase não se modificou, mantendo-se incompatível com a realidade. À vista disso, as mudanças propostas pelo manifesto acabaram por impulsionar o crescimento espontâneo da educação, mas este aumento se deu de forma desordenada e com alguns agravantes. Dentre eles, podemos afirmar que houve a redução da ação direta do poder público, federal e estadual. 
O que ficou latente em nossa pesquisa é que as ações propostas no manifesto de 1932 não se efetivaram, embora a maioria dos signatários tivessem assumido postos importantes nos governos e na educação, tanto na esfera federal quanto estadual. Em realidade houve pouco interesse por parte do Estado pela educação pública, e isso aumentou, ainda mais, a escassez de recursos aplicados à educação em algumas regiões, principalmente no norte e no nordeste. Em função da nova e contraditória dinâmica política, a orientação pela descentralização nas políticas públicas passou a conviver com o excesso de centralização (LIMA, 2017).

De acordo com o manifesto de 1959, o que ocorreu foi que passamos a conviver com a falta de espírito público, o diletantismo e a improvisação. Para Azevedo et al (2006), o Brasil, ao invés de tomar medidas de investimento em educação preferiu investir mais na industrialização, e preteriu a educação primária e a maioria da população (FREITAS, 2018, p. 194.).

Após os dois manifestos, a esperança era que tivesse havido mudanças fundantes, mas isso não ocorreu. D Ávila (2006), ao estudar o tratamento dado à população não branca e pobre no Rio de Janeiro na década de 1940 e também, as influências dos manifestos, em especial o de 1932, percebeu que as práticas utilizadas nas escolas públicas cariocas, o objetivo foi ofertar a população negra, a cultura branca, a higienização, a eugenia, o comportamento adequado, para que elas fossem esbranquiçadas e pudessem até ter a sua cor de pele transmutada.

Faz crítica relevante aos reformadores de 1932:

Os condutores da expansão e da reforma educacional acreditavam que a maior parte dos brasileiros, pobres e/ou pessoas de cor, eram subcidadãos presos a degeneração - condição que herdavam de seus antepassados e transmitiam a seus filhos, enfraquecendo a nação. Os mesmos educadores também, tinham fé em sua capacidade de mobilizar ciência e política para redimir a população, transformando-a em cidadãos-modelo(...). As práticas educacionais discutidas aqui eram uma faca de dois gumes. Por um lado, criaram novos recursos e novas oportunidades direcionadas a pessoas historicamente excluídas. Por outro, participantes na educação pública foram tratados de maneira desigual - os alunos pobres e de cor foram marcados como doentes, mal-adaptados e problemáticos (D’ÁVILA, 2006, p. 13).

O autor buscou perceber como a educação se expandiu e foi reformada de maneira que legitimasse desigualdades raciais e sociais, mesmo quando parte dos discursos diziam o contrário. Para ele, a concepção subjetiva de inferioridade dos alunos e alunas pobres, não brancos constituiu 0 conceito de mérito usado para distribuir ou delimitar recompensas educacionais. (FREITAS, 2018). Tal forma de pensar não mudou nas ações após o manifesto de 1959, mas se revelaram como potentes visões da inferioridade da população pobre e negra no tocante à educação.

Os reformadores de 1932 descreveram que a "educação é frequentemente impedida ou mutilada pela ignorância dos pais ou responsáveis e pelas contingências econômicas" (AZEVEDO et al, 1984, p. 414). Foi a partir dessa dinâmica que percebemos um dado real em nossa sociedade. A 
SOCIEDADE CIVIL E BASES DA EDUCAÇÃO: novo tempo para manifestos ou manifestos para novo tempo?

sociedade brasileira e, em especial, a educação se estruturou com base nas desigualdades de renda, classe, raça e gênero. Sendo possível observar, ao longo desse processo, que faz bastante diferença ter ou não ter dinheiro, terra e/ou educação superior.

Portanto, os reformadores da educação, creditaram junto com outros atores, que os problemas educacionais vinham das condições sociais, culturais ou ambientalmente inadequadas. Eles atribuíram os possíveis distúrbios das crianças a péssimas influências em suas casas ou comunidade. Nesse sentido, D'Ávila (2006) discute que o fato de culpar pais e comunidade pelos possíveis desajustes das crianças significou culpar sua cultura e cor de pele. Os dois manifestos, apesar dos avanços e ações, acabaram por fortalecer as bases econômicas e desiguais da educação brasileira. Porém ressaltamos que os signatários dos manifestos fizeram suas ações com a firme ideia de uma política pública que garantisse uma escola única, pública, laica e universal. No entanto, essas ideias e proposições educativas conviveram:

a) no espaço da escola pública, com as visões desiguais (advindas desde o período colonial) em relação a renda, raça, gênero e classe; b) no espaço político, com a força e o poder da classe dominante e do Estado, ou seja, da oligarquia rural, da elite burguesa e dos regimes militares. Nesse contexto se construiu a política educacional (FREITAS, 2018, p. 198)

No entanto é importante ressaltar que o Brasil ainda não havia experimentado um processo democrático. A partir de 1984, com a Campanha das Diretas Já, a sociedade civil intensificou a luta pelo regime democrático e de direitos avançando nesse campo. Novos atores entram em cena e passam a influenciar no âmbito das decisões públicas.

\section{VOZES DA EDUCAÇÃO E AÇÃO POLÍTICA DA SOCIEDADE CIVIL: o ontem e o hoje}

Na dinâmica nova da sociedade, buscando direitos e democracia, é que começou a ser possível identificar a criação de espaços de participação. Com relação aos instrumentos de ação pública, no campo educativo podemos citar o Fórum da Educação na Constituinte, que fez o movimento em defesa da educação. O Fórum lançou o Manifesto em Defesa da Escola Pública e Gratuita (FÓRUM DA EDUCAÇÃO, 1987). No manifesto reivindicavam o fim das concepções técnicoburocráticas da gestão escolar (advindas das novas pedagogias) e a especificidade do trabalho na escola. Para Saviani (1992), o fórum e seus representantes estavam preocupados com a organização da escola democrática que eliminasse a estrutura autoritária hierárquica que potencializava uma organização escolar fincada nas relações de poder e na submissão.

Esse manifesto denuncia, mais uma vez, o descompromisso do poder público com a população e revela o fato de a educação ser tratada como mercadoria: 
Os problemas centrais da educação no Brasil são o descompromisso do poder público com a educação e a privatização do ensino, resultante do baixíssimo nível de escolaridade da população. Fugindo à sua responsabilidade social com o ensino e a produção do saber, 0 governo desenvolve uma política educacional que favorece o empresariamento do ensino, tratado como mercadoria (FÓRUM DA EDUCAÇÃO, 1987).

O manifesto de 1987 tinha basicamente como princípios que a) a educação é direito de todo cidadão, ensino público gratuito e laico em todos os níveis; b) o governo federal destinaria ao ensino público e gratuito não menos de 13\%, outros governos aplicariam no mínimo, 25\%; c) verbas públicas destinam-se exclusivamente às escolas públicas e d) a democratização da escola quanto ao acesso, permanência e a gestão. O fórum e o manifesto são fruto dos resultados políticos da IV Conferência Brasileira de Educação (CBE), realizada um ano antes, em setembro de 1986, onde saiu uma carta intitulada a Carta de Goiânia.

Desejamos ressaltar que a sociedade civil percebera no processo de desenvolvimento nacional, que a busca por lucro e dinheiro é algo basilar na sociedade e na educação, porém não perceberam as desigualdades de classe, renda, raça e gênero como bases que estruturaram a educação, embora fizessem parte da agenda de lutas a diminuição da desigualdade social e a justiça social. Tanto os manifestos que utilizamos como fontes quanto os autores estudados viram no processo de desenvolvimento, apenas, o aprofundamento das desigualdades, ou seja, entenderam as desigualdades como resultado do processo. No entanto, em nossa história no campo educativo, as desigualdades foram estruturadoras das políticas públicas de educação². Consequentemente, verificase seguidamente no estudo, que não só essa estrutura se manteve, como vai se aprofundar por meio das reformas, leis e da política educacional e nacional.

Em continuidade, na Carta de Goiânia da IV CBE, assim está descrito,

Dados divulgados pelo próprio Governo Federal mostram que cerca de $60 \%$ dos brasileiros encontram-se em estado de extrema pobreza material, em contraste com uma minoria de grupos privilegiados que detêm o usufruto privado da riqueza que é social. Isso significa que as aspirações da coletividade pela democracia econômica, social e política são obstaculizadas por uma organização social injusta e, em decorrência, por políticas governamentais incapazes de promover a justiça social. Persiste uma política econômica, e particularmente salarial, marcada pela distribuição desigual da renda, cujas expressões são a questão agrária e a violência social contra os trabalhadores rurais; o enorme endividamento externo; a dívida pública; o precário atendimento às necessidades de escolarização da população e a outras necessidades sociais como saúde, assistência e previdência social (IV CBE, 1986).

Foi a partir dessa luta pela democracia e da organização da classe trabalhadora nos anos 1980, que a sociedade civil conseguiu escrever alguns artigos importantes na Constituição de 1988. No quesito educação foram colocados alguns dispositivos constitucionais. Freitas, (2018, p. 209), afirma: 
SOCIEDADE CIVIL E BASES DA EDUCAÇÃO: novo tempo para manifestos ou manifestos para novo tempo?

colaboração da sociedade, e esses últimos não constam da reivindicação do Manifesto de 1986, que inscreveu este dever unicamente no âmbito do Estado. Percebe-se no artigo 206, que se conseguiu inscrever na lei, dentre outras coisas, a gratuidade, igualdade no acesso e a permanência, pluralismos de concepção pedagógica, valorização dos profissionais de ensino e padrão de qualidade. Pontos que estão em acordo com as reinvindicações dos Manifestos de 1871, 1932, 1959, 1986 e 1987.

Contudo, não se deve perder de vista, que mesmo os direitos estando inscritos em lei e assim sejam oficiais, no Brasil, isso não significa a garantia real. Com a elite no poder e sendo quase sempre a classe dominante, mais uma vez, negociou seus interesses em prol dos avanços que se faziam necessários para o desenvolvimento, com foco no lucro do capital nas mãos de poucos. Isso se refletiu nos artigos constitucionais, pois apesar de garantir educação para todos, fator determinante para o desenvolvimento humano, social, político e econômico, alguns artigos mantiveram os ideais privatistas e de baixo investimento na política pública educacional.

Com base no art. 214 da Constituição Federal de 1988, e após as lutas dentro do congresso nacional, é promulgada LDB 9.394/96, que em seu art. 87 preconiza "que atribui à sociedade a elaboração do Plano Nacional de Educação, PNE" (II CONED, 1997). A Comissão Organizadora do II Congresso Nacional de Educação (CONED), elaborou uma proposta de Plano Nacional de Educação, por meio da sistematização das discussões feitas no I e || CONED, nas resoluções do Conselho do ANDES - Sindicato Nacional (CONAD), em encontros e seminários por todo o país. A proposta foi o resultado do II CONED.

As lutas e disputas se sucederam nos governos da década de 1990, de Fernando Collor de Mello e Fernando Henrique Cardoso, e depois continuaram nos anos 2000 nos governos de Fernando Henrique Cardoso, de Luiz Inácio Lula da Silva e Dilma Rousseff. Nesses períodos, a partir de 1995, após debates extensivos, audiências públicas e conferências a sociedade civil avançou e emplacou novas mudanças constitucionais, (II CONED, 1997). Os avanços da sociedade civil na garantia de participação nas decisões públicas começaram a ocorrer nos anos 1990. No entanto, a ação pública e seus instrumentos de gestão foram mais perceptíveis a partir de 2003.

Algumas medidas e mudanças constitucionais foram feitas para incluir as pautas de interesse da sociedade civil e dos profissionais da educação que começaram a ser passíveis de controle social. O governo, em consonância com a sociedade civil, começou a criar instrumentos de gestão pública como o Fórum Nacional de Educação (FNE), e ampliar os espaços de participação na construção das políticas públicas. Percebe-se que, principalmente, no governo do Partido dos Trabalhadores (PT) de 2003-2010, algumas das reivindicações históricas descritas nos manifestos se fizeram presentes, inclusive, com mudanças no texto Constitucional.

É possível observar os avanços dos governos do PT por meio da construção de espaços políticos de ação pública, e pelos números concretos do investimento na educação pública. A 
Organização para Cooperação e Desenvolvimento Econômico- OCDE (2014), afirmou que o número de matrículas de crianças de quatro anos de idade teve um salto de 24\%, de 2005 a 2014, e atingiu 0 percentual de cobertura de $61 \%$ da população nessa faixa-etária. As ações dos governos com o Pacto Nacional pela Alfabetização na Idade Certa (PNAIC) garantiram a ampliação da duração do ensino fundamental para nove anos, com quase 100\% das crianças de 6 a 14 anos na escola e a alfabetização de crianças até oito anos de idade. Além da obrigatoriedade do ensino dos 4 aos 17 anos (OCDE, 2014).

Mesmo com tudo isso, as mudanças realizadas não foram suficientes para a transformação necessária das bases que estruturaram a educação. Mesmo considerando que as mudanças não se centraram nessas bases é relevante destacar que trouxeram resultados positivos, tais como as políticas afirmativas, as exigências da educação para o acesso ao bolsa família, o Piso salarial, a valorização dos professores. Outra mudança foi o aumento na fonte de financiamento da educação pública com o salário-educação. No entanto, 0 art. 213 da Constituição se manteve na íntegra, e continuou a garantir dinheiro público para iniciativa privada (BRASIL, 2018).

Ao debruçar sobre os manifestos e as leis, percebeu-se que nem sempre o que está garantido é cumprido. Todavia, no jogo de interesse político brasileiro o que fica estabelecido tem trazido resultados mais favoráveis às classes dominantes, em especial, a elite conservadora e burguesa, mesmo quando historicamente a classe trabalhadora tem feito a luta em sentido contrário.

Essa garantia de ganhar o jogo para a classe dominante brasileira tem sido potencializada pelas decisões dos governos tanto nos períodos militares quanto na democracia. Os acontecimentos no processo de elaboração da LDB, Lei 9.394 de 1996, por exemplo, não garantiram as discussões democráticas realizadas por meio dos instrumentos de ação pública criados para esse fim. No momento de sua aprovação, segundo (MELO; MARQUES, 2016), a manobra feita no parlamento em conjunto com o MEC mudou o documento e aprovou outro que não foi validado pela sociedade civil. Assim, é pertinente considerar a democracia no Brasil como um processo em transição e que precisa se consolidar, por meio da ação pública e da democracia radical. Entretanto, apesar disso tudo, a sociedade civil conseguiu avançar e garantir alguns dos seus interesses políticos e econômicos, fortalecendo a ação contra-hegemônica.

Além disso, o Brasil se desenvolveu sob a égide do capitalismo mundial. Como observado, esse modo de produção tem por caraterística estabelecer relação desigual entre classes e entre os países, em especial, com as colônias. Esse modo de desenvolvimento desigual se reproduziu em nossa sociedade. Então, o resultado foi historicamente, a péssima distribuição de renda, o latifúndio e as desigualdades (LOWY, 2015). Desta forma, o processo de redemocratização representou muito mais uma transição política de um regime para outro do que transformações efetivas, pois a 
SOCIEDADE CIVIL E BASES DA EDUCAÇÃO: novo tempo para manifestos ou manifestos para novo tempo?

democracia no país, em que pese ter sido propulsora de mudanças foi incapaz de promover alterações estruturais nas bases políticas, econômicas e sociais.

O I PNE, aprovado e instituído em 2001, a exemplo da LDB, Lei 9.394 de 1996 passou por muitas mudanças dentro do Congresso e do executivo, e não respeitou as contribuições da sociedade civil (CONAPE, 2018).

Foi marcado por fortes embates entre as propostas encampadas pela sociedade civil e movimentos ligados a educação e as propostas do governo federal. De fato, dois projetos alternativos tramitaram em conjunto, e o texto final sancionado em 2001, apesar de incorporar algumas metas do plano defendido pela sociedade, acabou consagrando a maior parte do texto enviado pelo Executivo. Além disso foram vetados aspectos considerados cruciais para a sustentação financeira das metas, como a previsão de gastos em educação se elevassem a 7\% do produto interno bruto (PIB) (BRITTO, 2015, p. 21).

E assim, é lançado o Manifesto da CONAPE (2017) que avaliou que o I PNE não teve legitimidade e nem deu grandes contribuições à educação brasileira, mesmo com uma duração de 10 anos. Em 2009, se iniciaram as discussões do II PNE, por meio da Emenda Constitucional (EC) no. 59 com inclusão no art. 214 da Constituição. Este contou com a realização e a contribuição da Conferência Nacional de Educação (CONAE) de 2010, com mais de 3 mil delegados, e com a participação dos atores sociais do campo da educação. Embora toda a trajetória e o planejamento das ações políticas e propostas tenham sido construídas por meio dos consensos entre os interesses em disputa, não muito diferente dos governos anteriores, a proposta enviada para a Câmara estava aquém das discussões realizadas e sugestões feitas durante os debates (MANIFESTO CONAPE, 2017).

O governo, ao ser assumido em 2016, por Michel Temer, interrompeu as mudanças que vinham ocorrendo no campo da educação ao aprovar leis, tais como a Lei $n^{0} 13.415 / 16$, portarias Portaria MEC $n^{0} 727 / 17$, decretos Decreto (sem número) de 27 de abril de $2017^{3}$, e propor emendas constitucionais (EC 95/16), que têm enfraquecido cotidianamente a democracia que ainda se encontra em construção, e estabelecido um caminho de abertura neoliberal (a exemplo dos anos de 1990) no que tange ao desenvolvimento nacional, com privatizações de empresas nacionais e cortes nos gastos sociais, como já descrito anteriormente e apontado no Manifesto da CONAPE 2017.

Após um golpe administrativo, o governo Temer tomou medidas no campo da educação que foram de encontro aos avanços da construção feita nas duas últimas décadas. Tal fato gerou bastante controvérsia, pois a sociedade civil já estava mobilizada para o trabalho com o II PNE. Porém, o governo federal publicou a Portaria n 577/17 e o Decreto (sem número) de 27 de abril de 2017, que convocou a CONAE e impôs, à revelia dos outros normativos, uma nova composição do Fórum Nacional de Educação (FNE) que era o coordenador da CONAE, e excluiu muitas entidades do FNE (ANPED, 2017). 
Foi a partir desses atos governamentais, que algumas instituições da sociedade civil e apoiadores da democracia na política, saíram do Fórum Nacional de Educação (FNE), criaram o Fórum Nacional Popular de Educação (FNPE) e lançaram em 20 de junho de 2017, o Manifesto em prol da democracia e da educação transformadora e convocaram a CONAPE2018. O manifesto, elaborado no âmbito da Comissão Executiva do Comitê Nacional de Luta em Defesa da Educação Pública, evidenciou a conjuntura atual da educação no país. Além disso, reafirmou e chamou a Conferência Nacional Popular de Educação (CONAPE), como estratégia de resistência das entidades e organizações do campo educacional, e de todos os que defendem a educação pública, gratuita e de qualidade referenciada socialmente (MANIFESTO CONAPE, 2017).

A Comissão abre o manifesto admitindo o amplo e democrático processo de participação da sociedade civil no governo anterior, nas etapas preparatórias realizadas em todas as esferas de governo (federal, estadual e municipal), e na realização da $2^{\text {a }}$ Conferência Nacional de Educação (CONAE/2014). As ações haviam, segundo os signatários do manifesto, contribuído inegavelmente com o avanço das políticas de educação, especialmente, para o estabelecimento do Plano Nacional de Educação (PNE) (2014/2024), como também, para a elaboração ou adequação (quando necessária) dos planos estaduais/distrital e municipais de educação correspondentes, bem como para a sua implementação e avaliação (MANIFESTO CONAPE, 2017).

O documento produzido na CONAE (2014) constituiu-se como o principal subsídio para o processo de mobilização e debate, permanentes, entre os trabalhadores da educação, o Estado e a sociedade civil. No manifesto está clara a noção da emergência do compromisso com a criação do Sistema Nacional de Educação. Compromisso que passava ainda, pela implementação e avaliação do PNE e os correspondentes planos decenais discutidos e/ou aprovados pelas câmaras municipais e assembleias legislativas em todo o país. A perspectiva desse pacto social firmado entre a sociedade civil organizada e o Estado é o de que um projeto de desenvolvimento nacional sustentável e soberano do Brasil não prescinde - pelo contrário, necessita - de uma educação verdadeiramente democrática, a qual só se assegura por meio do fortalecimento da educação pública, gratuita, inclusiva, laica e de qualidade e, de outro lado, da regulamentação da educação privada, com a exigência do cumprimento do papel do Estado no controle, regulação, credenciamento e avaliação da educação, com as devidas referências sociais (MANIFESTO CONAPE, 2017, p. 1).

É perceptível no discurso, o reconhecimento dos avanços no campo da educação e também, como a sociedade civil tem plena consciência de sua importância para o desenvolvimento sustentável, democrático e soberano. No entanto, este pacto não só foi rompido como passou a invalidar a trajetória feita por meio de ação pública e política, mesmo com todos os conflitos, disputas e interesses sempre em jogo. O manifesto assim descreve: 


\begin{abstract}
Esse pacto foi rompido pela implementação das políticas ilegítimas de Michel Temer. Rompido pela entrega do pré-sal, cujos royalties seriam destinados para a educação, aos interesses estrangeiros e pela Emenda Constitucional 95, que, ao congelar por 20 anos os investimentos em políticas públicas no país, inviabilizou por completo o cumprimento das diretrizes e metas do PNE, incluindo a mais conhecida delas: a destinação de $10 \%$ do Produto Interno Bruto (PIB) brasileiro para a educação. Rompido pela suspensão de programas e políticas de acesso que afetam a garantia constitucional de universalização da educação básica e expansão da educação superior. Rompido pela reforma do ensino médio feita arbitrariamente via medida provisória, sem discussão com educadores e entidades do campo educacional, e que torna essa etapa da educação básica ainda mais excludente, rebaixando a formação e visando ao desmanche e à privatização da escola pública. Rompido pela aprovação da terceirização irrestrita, inclusive para atividades-fim, medida cujos efeitos são a precarização nas relações de trabalho e ampliação da degradação das condições de trabalho, a supressão dos direitos dos trabalhadores, o rebaixamento salarial, a perda de direitos sociais e a redução da representação sindical, sem contar o grave prejuízo à qualidade do ensino e ao projeto pedagógico das instituições. Rompido pela leniência - ou, de fato, conivência do Poder Executivo - com tentativas explícitas e espúrias de censura e criminalização do magistério, como a simbolizada pela parcialidade do movimento Escola Sem Partido e suas propostas de implementação de leis da mordaça em todo o país. Rompido pelo aparelhamento do Conselho Nacional de Educação (CNE), pela ingerência e recomposição à revelia do Fórum Nacional de Educação (FNE) - com a exclusão de entidades históricas do campo educacional e a abertura do órgão aos interesses do capital privado - e pela nítida intenção do Ministério da Educação de inviabilizar a realização de uma CONAE/2018 nos moldes democráticos e com ampla participação social (MANIFESTO CONAPE, 2017, p. 1)
\end{abstract}

Ao não permitir a realização da CONAE/2018, que tinha o tema: A consolidação do Sistema Nacional de Educação (SNE) e o Plano Nacional de Educação (PNE): monitoramento, avaliação e proposição de políticas para a garantia do direito à educação de qualidade social, pública, gratuita e laica, o governo revelou os seus intuitos de não respeitar a construção dos atores coletivos, e seguir fortalecendo as bases estruturantes da educação e as orientações capitalistas neoliberais e antidemocráticas.

Com toda essa conjuntura o novo FNPE, por meio do Manifesto CONAPE, Vozes da Cidadania, convocou a CONAPE 2018, e assim afirmou:

Sem a reflexão sobre uma concepção pedagógica crítica, o enfrentamento das políticas ilegítimas deste governo e a construção do Sistema Nacional de Educação, com fortalecimento da escola pública e regulamentação do ensino privado, não há projeto democrático de educação. Para isso, o movimento educacional necessita mostrar que o desenvolvimento da educação não se dá apenas no âmbito da luta educacional, mas também no enfrentamento à exclusão, à concentração de renda e às disparidades regionais e sociais, consequências de uma noção de desenvolvimento baseada no consumo, que acirra a desigualdade e à qual 0 combate exige ações políticas e sociais articuladas (MANIFESTO CONAPE, 2017, p. 2).

O movimento em torno da CONAPE 2018 entendeu que a luta não se dá apenas no campo da educação. Como se pode observar na citação acima do manifesto, o mesmo propõe que se atue "no enfrentamento à exclusão, à concentração de renda e às disparidades regionais e sociais, consequências de uma noção de desenvolvimento baseada no consumo, que acirra a desigualdade" 
(MANIFESTO CONAPE, 2017, p. 2). Esse discurso revela, mais uma vez, a visão de que existem as desigualdades, mas as mesmas são encaradas como o resultado do desenvolvimento baseado no consumo e não como o que o estruturou e está secularmente sendo sedimentado.

Essa visão é recorrente em quase todos os documentos e textos publicados pela sociedade civil; não se percebeu ainda o fino fio ideológico das ideais forças da hegemonia da classe dominante. Nesta pesquisa, o que descobrimos foi que as desigualdades estão na base da estrutura social e na ideologia (por meio de seus aparelhos, em especial a mídia) que historicamente a sustenta, e assim a hegemonia acaba por permanecer com a classe dominante e o capital.

Atualmente, apesar dos discursos do governo focados no desenvolvimento e crescimento do país, o que se percebe é a aposta na privatização de setores importantes, setores nos quais havia sido prevista a garantia no aumento do financiamento das políticas sociais, em especial, de educação e saúde. Para ilustrar apresento o caso da Petrobrás, com a descoberta do pré-sal e sua exploração ficou prevista em lei e no PNE a ampliação dos investimentos em educação e saúde, no entanto, o governo ignorou o dever de cumprir a lei e privatizou essa empresa.

Portanto, a política de desenvolvimento brasileiro, com o processo de privatização e a política de educação com o corte de gastos, na atualidade, age no sentido contrário do que estava sendo realizado em relação ao desenvolvimento nacional e à educação, e ideologicamente atua em tentar garantir o consenso da sociedade em torno de suas propostas. Um dos mecanismos poderosos utilizados é o da mídia, que no Brasil é reconhecidamente monopolizada por algumas famílias.

Nessas condições, a educação é estratégica para a formação crítica e reflexiva, porquanto, quando a comunidade escolar não percebe os processos de avanço no campo do saber e da ciência, como também das novas exigências tecnológicas, não poderá avançar na luta por direitos. Quando uma população não percebe os processos e políticas que visam desenvolver comportamentos distantes da realidade e ideologizantes, ambos servidos à vontade em todo o tecido social, as transformações não ocorrem. Essa dinâmica é vivida todos os dias pelas crianças e pela juventude, inclusive, dentro de muitas escolas e salas de aula. Quando percebemos que a base que estruturou e ainda estrutura a educação no Brasil são as desigualdades, essas mantidas por correntes ideológicas que impõem a sua visão de mundo e de sociedade, não se mudará a hegemonia da classe que vive da exploração do trabalho e do lucro financeiro. Um dos possíveis caminhos aqui apontados é a democracia radical e a ação pública.

Após a realização da CONAPE 2018 foi publicado um novo manifesto: "CONAPE/2018 'LULA LIVRE': A EDUCAÇÃO COMO ESPAÇO DE RESISTÊNCIA. MANIFESTO: Carta de Belo Horizonte" (CONAPE, 2018, p. 1). O documento assim inicia: 
No momento atual de crise que passa o Brasil, com o aprofundamento do golpe deflagrado em 2016, a partir da destituição do governo legitimamente eleito de Dilma Rousseff, a luta pela educação não pode estar desatrelada daquela em defesa da restauração do Estado Democrático de Direito. Os processos de ruptura democrática pelos quais passou o país guardam, em comum, a redução drástica dos direitos sociais, entre os quais a educação um dos pilares inquestionáveis de qualquer democracia -, alvo de severos ataques políticos, econômicos e pedagógicos que visam desestruturar a possibilidade de formação crítica e cidadã. Foi assim com a instituição do Estado Novo, em 1937, que pôs fim aos avanços conquistados na Constituição democrática de 1934. Foi assim em 1964, com 0 golpe civil-militar que depôs João Goulart e enterrou a Carta de 1946. E é assim agora, com a série de medidas golpistas que buscam sepultar a Constituição de 1988 - incluindo seu artigo 205, que assegura a educação como dever do Estado e direito de cada cidadão - 30 anos após sua promulgação (CONAPE, 2018, p. 1).

O manifesto apresenta várias questões de cunho político, econômico e social, apresenta sua pauta de luta e reivindicações,e, a exemplo do manifesto de 1871 , convoca a população para se mobilizar, agora em torno da democratização dos direitos e pela defesa da educação, diante dos ataques diretos aos serviços públicos e do favorecimento da privatização. Ao analisar a pauta destacamos que ainda se encontram temas que são históricos e reivindicados secularmente.

\section{CONCLUSÃO}

As profundas desigualdades constituíram a nossa sociedade e nosso modelo educativo, com a manutenção da riqueza nas mãos de poucos desde a nossa formação. É relevante perceber que as reformas educativas foram e são justificadas pela necessária modernização e desenvolvimento do país que carece de força de trabalho, adequada aos novos processos de produção. $O$ foco no discurso é sempre a formação e escolarização de força de trabalho.

Os manifestos de 1871, de 1932, de 1959, de 1986, de 1987, de 2017 e de 2018 encontram-se profundamente marcados pela atmosfera social, política e econômica de cada época, sempre apontaram para as desigualdades e a necessidade da participação e do controle social. Com base na ação pública e em seus instrumentos políticos de gestão foi possível observar esse potente movimento. No entanto, as desigualdades são vistas como resultado do processo e não como estrutura basilar. Considerando a estrutura fundante da educação em relação ao modo de desenvolver brasileiro, é possível compreender a dinâmica política, econômica e social nos dias atuais.

Tal processo sofre a desconstrução porque foi edificado em bases injustas, e assim 0 governo não permite que decisões sejam tomadas por todos os envolvidos. Imbuídos e determinados em não permitir a ação pública passam a limitar os espaços da participação nas decisões em políticas públicas. $E$ tentam, com isso, assumir a centralidade, embora isso possa não ocorrer. A limitação pode ser claramente observada com a edição do Decreto, No. 9.759, de 11 de abril de 2019, que extinguiu inúmeros espaços de participação, para serem renormatizados por meio da limitação da participação. 
Revogou o Decreto No. 8.243, de 23 de maio de 2014, que havia instituído, ainda que tardiamente, a Política Nacional de Participação Social - PNPS e o Sistema Nacional de Participação Social - SNPS, no Brasil. Portanto, a luta é urgente e cada vez mais exigente.

\section{REFERÊNCIAS}

ALVES, A. R. O conceito de hegemonia: de Gramsci a Laclau e Mouffe. Lua Nova, 71-96, 2010.

AZEVEDO, F. D., et al. Manifesto dos pioneiros da educação nova: a reconstrução educacional no Brasil - ao povo e ao governo. Revista Brasileira de Estudos Pedagógicos, 407-425, 1984.

205-220, 2006. Manifesto dos educadores: mais uma vez convocados. Revista HISTEDBR,

CARVALHO, J. M. Cidadania no Brasil: o longo caminho. Rio de Janeiro: Civilização Brasileira, 2008.

CONAPE, V. D. Manifesto em prol da democracia e da educação transformadora, 2017.

CONAPE. Lula Livre: a educação como espaço de resitência. Manifesto: Carta de Belo Horizonte. Belo Horizonte, Minas Gerais, Brasil: Fórum Nacional Popular de Educação, 2018.

CUNHA, L. A. A educaçaõ brasileira na primeira onda laica: do império à república. Rio de Janeiro: Edição do Autor, 2017.

D’ÁVILA, J. Diploma de brancura: política social e racial no Brasil - 1917-1945. São Paulo: UNESP, 2006.

FERREIRINHA, Isabella Maria Nunes; RAITZ, Tânia Regina. As relações de poder em Michel Foucault: reflexões teóricas. RAP/FGV, RJ.44(2):367-83, mar./abr. 2010.

FÓRUM DA EDUCAÇÃO, N. C. Manifesto em defesa da escola pública e gratuita. Brasília, DF: Fórum da Educação na Constituinte, 1987.

FREITAS, Urânia Flores da Cruz. Desenvolvimento à Moda Brasileira: dinheiro e desigualdades como bases estruturantes da educação. Tese (Doutorado em Desenvolvimento Sociedade e Cooperação Internacional). Interdisciplinar. PPGDSCI/CEAM/UnB, Brasília, 2018.

FRIGOTTO, G. A produtividade da escola improdutiva: um (re) exame das relações entre educação e estrutura econômico-social e capitalista. São Paulo: Cortez Editora, 2001.

GRAMSCI, A. Maquiavel: a política e o estado moderno. Rio de Janeiro: Civilização Brasileira, 1968.

II CONED, C. O. Plano Nacional de Educação: a proposta da sociedade brasileira. Belo Horizonte, 1997.

IV CBE, C. d. Carta de Goiânia - IV CBE. Goiânia, Goiás, Brasil. (2-5 de setembro de 1986).

LASCOUMES, P. ; LE GALÉS, P. Sociologia da ação pública. Alagoas: Edufal. 2012. 
SOCIEDADE CIVIL E BASES DA EDUCAÇÃO: novo tempo para manifestos ou manifestos para novo tempo?

LATOUR, B. Reagregando o social. Salvador/Bauru: EDUFBA / EDUSC, 2012.

MANIFESTO DOS PROFESSORES, p. d. Instrução Pública. Manifesto dos professores públicos de instrucção primária da corte. Revista da História da Educação - RHE, p. 177-197, 2011.

MARX, K. O capital: crítica da economia política: Livro I: o processo de produção do capital. São Paulo: Boitempo editorial, 2013.

OECD. Regards sur l'éducation 2014. Disponível em: http://www.oecd.org/education/Regards-surl'education-2014.pdf. Acesso em: 6 set. 2018.

PILETTI, N. História da Educação no Brasil. São Paulo: Editora Ática, 1991.

ROMANELLI, O. d. História da educação no Brasil. Petrópolis: Editora Vozes, 1978.

SAVIANI, D. Escola e Democracia. São Paulo: Editora Autores Associados, 1992.

TEIXEIRA, A. Valores proclamados e valores reais nas instituições escolares brasileiras. Revista Brasileira de Estudos Pedagógicos, p. 59-79, 1962.

\section{Notas}

1 Os originais podem ser encontrados na Biblioteca Nacional do Rio de Janeiro, a quem agradeço toda a atenção e orientação dada para ter acesso ao texto.

2 Pensar em políticas públicas de educação no Brasil só é possível a partir da década de 1930. Nesse período, a educação é pensada em âmbito nacional. A partir da criação do Ministério da Educação e da Reforma Francisco de Campos, identifica-se forte intenção em se criar uma política nacional de educação. Pensar a ação pública, apenas na década de 1990, o impulso e criação de instrumentos de gestão participativa foi maior nos anos 2000.

3BRASIL. Decreto 57597 de 26 de abril de 2017. Disponível em: http://www2.camara.leg.br/legin/fed/decret_sn/2017/decreto-57597-26-abril-2017-784646-publicacaooriginal-152411-pe.htm. Acesso em: 16 maio 2018. 